\title{
Soil Fertility Status in Coconut after Long-term Drip Fertigation in Indo-gangetic Plain of South Bihar Alluvial Zone(a)
}

\author{
Avinash Sarin Saxena ${ }^{1}$, Sankar Chandra Paul ${ }^{1}$, Amit Kumar Pradhan ${ }^{1}$, Rajiv Rakshit ${ }^{1}$, \\ Ruby Rani ${ }^{2}$, Deepak Ranjan Kishor ${ }^{3}$ and Chandan Kumar Bagchi ${ }^{2}$ \\ ${ }^{1}$ Department of Soil Science and Agricultural Chemistry, Bihar Agricultural University, \\ Sabour, Bhagalpur, India \\ ${ }^{2}$ Department of Horticulture (Fruit \& Fruit Technology), Bihar Agricultural University, \\ Sabour, Bhagalpur, India \\ ${ }^{3}$ Department of Entomology, Dr. Rajendra Prasad central Agricultural University, \\ Pusa, Samastipur, Bihar, India \\ *Corresponding author
}

\section{Keywords}

Physicochemical hydraulic, fertigation , drip organic carbon

\section{Article Info}

Accepted: 05January 2020 Available Online: 10 February 2020

\section{A B S T R A C T}

It was reported that water resources and ground water reduces day by day but its consumption in different sector increases rapidly. In India agriculture is largest water consumer (81\%) sector (WRI, 2007) and use of water in an efficient way is demand of time. It has been scientifically recognized that adoption of drip fertigation method is an option for efficient use of water and nutrients through improvement in crop yield per unit volume of water and nutrients used (Bar-Yosef, 1999; Patel and Rajput, 2011). Drip fertigation allows continuous irrigation and fertilizer injection into the root zone. Soil physicochemical properties are important aspects of soil quality that can change with long-term drip irrigation due to physical and chemical stress evidence of soil structural decline, such as increased bulk density under drip irrigation has been reported (Clark, 2004). Moreover, drip irrigation whereby a certain portion of the soil is wetted also causes the spatial variability of soil physical and hydraulic properties. Therefore, evaluation of spatial variability of soil characteristics and the vertical distribution of nutrients in soil under drip fertigation system can act as a very useful tool for the determination of fluctuations in soil behavior, especially its nutrient supplying capacity. Keeping the above facts in mind, the present investigation was carried out to know the soil fertility status under long-term drip fertigation system in coconut under All India Coordinated Research Project on coconut variety Shakhi Gopal Tall with long term drip fertigation system in BAU, Sabour under following treatments viz. T1 $=$ Control, $\mathrm{T} 2=25 \%$ of the recommended dose of NPK fertilizers (RDF) through drip system, T3 $=50 \%$ of the RDF through the drip system, $\mathrm{T} 4=75 \%$ of the RDF through the drip system, $\mathrm{T} 5=100 \%$ of the RDF through the drip system, T6 $=100 \%$ of the RDF through soil application. The results indicated that bulk density, particle density and pore space of soils were found to have no significant difference among the treatments and across different soil depths. Bulk density, particle density and pore space varied from 1.41 to $1.47 \mathrm{Mg} \mathrm{m}^{-3}, 2.23$ to $2.25 \mathrm{Mg} \mathrm{m}^{-3}$, and 31.9 to $36.6 \%$, respectively, among all soils. Void ratio varied from 0.51 to 0.59 over all the soils. Void ratio and air-filled porosity were not significantly different among the treatments but significant difference was observed across the soil depths. Maximum water holding capacity of soils under different treatments across varying soil depths was not significantly different from each other. Soil $\mathrm{pH}$ and $\mathrm{EC}$ of all the treatments was not significantly different but decreased significantly with increasing soil depths. All the treatments for CEC and organic carbon content of soils were not found to be significantly different and depthwise were significantly different. Organic carbon content varied significantly among all the treatments and also across the varying soil depths. Available nitrogen, phosphorus and potassium content were low, medium and low to medium respectively. All the treatments were significantly different for available nitrogen, phosphorus and potassium content in soil. Highest content of these three nutrients was found in T5 treatment. Sulphur content in soil was border of medium and all the treatments were at par. All the treatments values were not significantly different for available sulphur content in soil. Total nitrogen and potassium content in all the treatments were significant different but total phosphorus and sulphur content were not significantly different. Iron, manganese, zinc, copper and boron content in all the treatment were not significantly different from each other. Dehydrogenase activity of studied soil was increasing significantly with increasing levels of fertilizer in the treatments and was decreasing significantly across the soil depths. Majority of the physicochemical and biological properties of soil under the different fertigation levels do not differ significantly. 


\section{Introduction}

Coconut palm is committed to the land on which it is planted for several decades, where the soil physical and chemical environment plays a significant role in sustaining its productivity. Agriculture is by far the largest water consumer $(81 \%)$ in India (WRI, 2007) and hence more efficient use of water in agriculture needs to be the top most priority. Water input per unit irrigated area will have to be reduced in response to water scarcity and environmental concerns (INCID, 2006).

It has been scientifically recognized that adoption of drip fertigation method is an option for efficient use of water and nutrients through improvement in crop yield per unit volume of water and nutrients used (BarYosef, 1999; Patel and Rajput, 2011). Results from a study on the use of fertigation by Jat et al., (2011) from ICRISAT, suggests that, in order to make agriculture sustainable and economically viable, there is need to promote fertigation on a large scale by the concerned stakeholders/ farmers.

Although the use of chemical fertilizer is the fastest way for counteracting the pace of nutrient depletion, its increasing cost and limited availability, discourage the farmers from using these inputs in balanced proportions thereby paving way for the problems of environmental pollution. In order to sustain the quality and quantity of crop production system, maintaining and improving soil fertility is very important, and this can only be achieved by applying fertilizers either in inorganic or organic form (Efthimiadou et al., 2010).

Adeniyan \& Ojeniyi (2006) stated that the main purpose of fertilization in agriculture is to obtain a high yield and to enhance soil fertility. However, Amer et al., (2009) opined that soil nutrient status can be improved by fertilization but maximum plant growth could only be achieved when the nutrient availability coincides with water availability. Therefore, the development of water and fertilizer management technology that enhance efficient water use has become an important strategy to guarantee sustainable crop production.

Drip fertigation allows continuous irrigation and fertilizer injection into the root zone. Accurate application of $\mathrm{N}$ throughout the growing season reduces the potential for groundwater contamination from nitrate and may also enhance crop yield (Bucks and Davis, 1986). In fact, the recommended dose of fertilizer for a crop is developed considering all possible nutrient loss processes, and loss of nutrients through drip fertigation is minimum or negligible.

Therefore, crop may get full nutrition using low amounts of fertilizers than the recommended dose. Soil physicochemical properties are important aspects of soil quality that can change with long-term drip irrigation due to physical and chemical stress evidence of soil structural decline, such as increased bulk density under drip irrigation has been reported (Clark, 2004).

Moreover, drip irrigation whereby a certain portion of the soil is wetted also causes the spatial variability of soil physical and hydraulic properties. More results are needed for clear trends to emerge and to decide whether we can go for large scale application of drip fertigation by farmers in subtropical agro ecosystem in India.

Therefore, the evaluation of spatial variability of soil characteristics and the vertical distribution of nutrients in soil under drip fertigation system can act as a very useful tool for the determination of fluctuations in soil behavior especially its nutrient supplying 
capacity. Keeping the above facts in mind, the following investigation was carried out to know the the soil fertility status under longterm drip fertigation system in coconut.

\section{Materials and Methods}

This study was conducted under All India Coordinated Research Project on Coconut at Bihar Agricultural University, Sabour. Experimental site comes under tropical to sub-tropical climate condition and is characterized by hot desiccating summer, cold winter and moderate annual rainfall with latitude and longitude of $25^{\circ} 14^{\prime} 11^{\prime \prime} \mathrm{N}$ and $87^{\circ} 04^{\prime} 1.6$ ' E respectively.

Experimental area having silty clay loam soil. Here Coconut seedling was planted during 2009 with Plant to plant distance 25'x 25' both ways. Drip irrigation along with fertilizer application (Fertigation) was imposed in 2012 in a Randomized Block Design (RBD) with four (4) replications the treatment details are listed below: $\mathrm{T} 1=$ Control, $\mathrm{T} 2=25 \%$ of the recommended dose of NPK fertilizers (RDF) through drip system, $\mathrm{T} 3=50 \%$ of the RDF through drip system, $\mathrm{T} 4=75 \%$ of the RDF through drip system, T5 $=100 \%$ of the RDF through drip system, T6 $=100 \%$ of the RDF through soil application. Each treatment plot occupies four coconut palms.

Drip fertigation was done during dry season from October to May every year with 8 equal split application of fertilizer. The amount of fertilizers scheduled to be applied through direct soil application is split into two equal halves and was applied during April-May (pre monsoon season) and October-November (post monsoon season) every year.

Soil samples were collected at $1.0 \mathrm{~m}$ distance from the base of the coconut trunk during post monsoon season just before the starting of fertilizer application and drip irrigation system, with the help of Dutch auger at 0$30 \mathrm{~cm}, 30-60 \mathrm{~cm}$ and $60-90 \mathrm{~cm}$ (three depth). Collected soil sample were kept in polythene bag and further processed for analysis and also stored in refrigerator for study of biological parameters.

The bulk density (BD) of experimental area was determined by core method gravimetrically after drying soil sample at $105^{\circ} \mathrm{C}$ for 24 hour in oven up to a constant weight. The particle density was determined by pycnometer method. Maximum water holding capacity was determined by using Keen Raczkowaski box method (Keen and Raczkowaski, 1921).

$\mathrm{pH}$ and EC were measured by the method described by Jackson (1973). Cation exchange capacity was determined by neutral normal ammonium acetate ( $1 N$ NH4OAc) with the help of the method of Schollenberger as described in Black (1965). Organic carbon was determined by wet digestion method of Walkley and Black (1934) as described in Black (1965).

Available nitrogen was estimated by alkaline permanganate oxidation method as described by Subbaiah and Asija (1956).Available phosphorus content was estimated by Olsen's method (Olsen et al., , 1954). Available potassium and sodium in soil and vermicompost were determined by neutral ammonium acetate $(1 N)$ extract using flame photometer (Jackson, 1973).

Extraction of available sulphur was done by using $0.15 \% \mathrm{CaCl}_{2}$ as per the method of Williams and Steinbergs (1959) and the extracted sulphur was estimated by turbidimetrically method of Chesnin and Yien (1951) using a spectrophotometer at $420 \mathrm{~nm}$ wavelength. Available $\mathrm{Fe}, \mathrm{Cu}, \mathrm{Zn}, \mathrm{Mn}$ were estimated by Lindsay and Norvell (1978) method with the help of atomic absorption 
spectrophotometer. Available boron content was estimated by reflux method using $0.02 \mathrm{M}$ $\mathrm{CaCl}_{2}$ solution with using Azomethine- $\mathrm{H}$ as colouring agent as described by John et al., (1975).Total nitrogen present in soil was determined by standard method (Piper, 1966).

Total phosphorous of soil was determined by di-acid digestion and phosphorus in the digest was estimated by the vanadomolybdate yellow colour method (Page et al., 1982). Total potassium and sodium were determined by using known volume of digest (prepared as in total phosphorus) and estimated by flame photometer (Page et al., 1982).

Total sulphur in the digest was estimated by using $\mathrm{BaCl}_{2}$ crystal following the method of Chesnin and Yien (1951). Total micronutrient (Fe, $\mathrm{Cu}, \mathrm{Mn}, \mathrm{Zn}$ ) in soil sample were determined by known volume of digest (prepared as in total phosphorous) by Lindsay and Norvell (1978) method.

The total B content of soil filtrate was determined spectrophotometrically by using Azomethine- $\mathrm{H}$ method colouring agent as described by John et al., (1975) and dehydrogenase activity in soil was determined by spectrophotometric method as described by Klein et al.,(1971).

\section{Statistical analysis}

The mean value, critical difference, coefficient of variance of each parameter and the correlation coefficients between leaf nutrient contents and different soil chemical characteristics as well as available nutrients were calculated as per procedure referred in Gomez and Gomez (1983).

Microsoft excel package (Office - 2003) and Statistical Package for the Social Science (SPSS) were used for the analysis.

\section{Results and Discussion}

\section{Status of some physical properties of soil}

It was observed that the physical properties of soil under long term drip fertigation in coconut plantation changes in all depth that was presented in table 1 . There was nonsignificant difference among different treatments was found in case of bulk density across different soil depths and varied from 1.41 to $1.47 \mathrm{Mg} \mathrm{m}^{-3}$ (Table 1).

In surface soils it varied from 1.41 to $1.42 \mathrm{Mg}$ $\mathrm{m}^{-3}$, but the values increased with depths which might be due to compactness owing to the pressure of upper soil layers.

The magnitude of the increase of Bulk density with increasing soil depths under drip fertigation treatments ( $\mathrm{T} 1$ to $\mathrm{T} 5$ ) were very pronounced whereas in $\mathrm{T} 6$ treatment where $100 \%$ RDF was applied through soil application, it was less pronounced it may be due to continuous downward movement of minerals and clay particles with drip irrigation water for a long time (5 years) which leads to a deposit to the lower depths where the particles occupy the soil pores resulting in increase of the mass of soil per unit volume.

Similar report of increased bulk density within the soil profile due to fertigation was also coined by Cockroft \& Olsen (2000). The particle density of soils under all treatments was found to have a similar trend. No increase or decrease in particle density values was observed with increasing soil depths.

It varied from 2.23 to $2.25 \mathrm{Mg} \mathrm{m}^{-3}$ with a mean value of $2.24 \mathrm{Mg} \mathrm{m}^{-3}$ among the soils of all the treatments. Pore space in soils receiving different treatments along different soil depths was not significantly different. In surface soil, it varied from 36.5 to $37.1 \%$ (Table 1). 
Table.1 Effect of long term (5 years) fertigation on physical properties of soil under study

\begin{tabular}{|c|c|c|c|c|c|c|c|c|c|c|c|c|c|c|c|c|c|c|c|c|}
\hline \multirow[t]{2}{*}{$\begin{array}{l}\text { Treat- } \\
\text { ments }\end{array}$} & \multicolumn{4}{|c|}{ Bulk density (Mg m$\left.{ }^{-3}\right)$} & \multicolumn{4}{|c|}{ Pore space (\%) } & \multicolumn{4}{|c|}{ Void ratio } & \multicolumn{4}{|c|}{ Air-filled porosity } & \multicolumn{4}{|c|}{$\begin{array}{l}\text { Max. water holding } \\
\text { capacity }(\%)\end{array}$} \\
\hline & D1 & D2 & D3 & Mean & D1 & D2 & D3 & Mean & D1 & D2 & D3 & Mean & D1 & D2 & D3 & Mean & D1 & D2 & D3 & Mean \\
\hline $\mathbf{T 1}$ & 1.41 & 1.44 & 1.46 & 1.44 & 37.1 & 36.0 & 34.9 & 34.4 & 0.59 & 0.56 & 0.54 & 0.57 & 0.14 & 0.12 & 0.11 & 0.12 & 41.5 & 43.9 & 42.4 & 42.6 \\
\hline $\mathbf{T} 2$ & 1.41 & 1.46 & 1.46 & 1.44 & 36.7 & 34.8 & 35.0 & 34.7 & 0.58 & 0.53 & 0.54 & 0.54 & 0.15 & 0.12 & 0.11 & 0.13 & 41.6 & 41.8 & 45.4 & 42.9 \\
\hline T3 & 1.42 & 1.47 & 1.46 & 1.45 & 36.6 & 34.2 & 35.0 & 34.0 & 0.58 & 0.52 & 0.54 & 0.53 & 0.16 & 0.12 & 0.11 & 0.13 & 45.1 & 46.1 & 43.4 & 44.8 \\
\hline $\mathbf{T 4}$ & 1.41 & 1.46 & 1.47 & 1.45 & 36.9 & 35.0 & 33.9 & 34.4 & 0.58 & 0.54 & 0.51 & 0.53 & 0.16 & 0.12 & 0.11 & 0.13 & 46.0 & 44.0 & 41.5 & 43.8 \\
\hline T5 & 1.42 & 1.47 & 1.47 & 1.45 & 36.5 & 34.3 & 34.7 & 34.7 & 0.58 & 0.52 & 0.53 & 0.54 & 0.16 & 0.14 & 0.11 & 0.14 & 48.9 & 43.7 & 36.1 & 42.9 \\
\hline T6 & 1.42 & 1.43 & 1.43 & 1.43 & 36.5 & 36.4 & 36.6 & 31.9 & 0.57 & 0.57 & 0.58 & 0.55 & 0.17 & 0.12 & 0.12 & 0.13 & 44.4 & 41.9 & 42.2 & 42.8 \\
\hline Mean & 1.42 & 1.46 & 1.46 & & 36.7 & 35.1 & 35.0 & & 0.58 & 0.54 & 0.54 & & 0.16 & 0.12 & 0.11 & & 44.6 & 43.6 & 41.8 & 43.3 \\
\hline \multicolumn{21}{|c|}{$C D(p=0.05)$} \\
\hline $\mathbf{T}$ & \multicolumn{4}{|c|}{ NS } & \multicolumn{4}{|c|}{ NS } & \multicolumn{4}{|c|}{ NS } & \multicolumn{4}{|c|}{ NS } & \multicolumn{4}{|c|}{ NS } \\
\hline D & \multicolumn{4}{|c|}{ NS } & \multicolumn{4}{|c|}{ NS } & \multicolumn{4}{|c|}{0.04} & \multicolumn{4}{|c|}{0.02} & \multicolumn{4}{|c|}{ NS } \\
\hline TxD & \multicolumn{4}{|c|}{ NS } & \multicolumn{4}{|c|}{ NS } & \multicolumn{4}{|c|}{ NS } & \multicolumn{4}{|c|}{ NS } & \multicolumn{4}{|c|}{ NS } \\
\hline $\begin{array}{l}\text { CV } \\
(\%)\end{array}$ & \multicolumn{4}{|c|}{4.64} & \multicolumn{4}{|c|}{9.84} & \multicolumn{4}{|c|}{13.53} & \multicolumn{4}{|c|}{2.90} & \multicolumn{4}{|c|}{5.35} \\
\hline
\end{tabular}

D1: 0 - $30 \mathrm{~cm}$ soil depth, D2: 30-60 $\mathrm{cm}$ soil depth, D3: 60-90 $\mathrm{cm}$ soil depth

$\mathrm{T} 1=$ Control (No fertilizer)

$\mathrm{T} 2=25 \%$ of the recommended dose of NPK fertilizers (RDF) through drip system

$\mathrm{T} 3=50 \%$ of the RDF through drip system

$\mathrm{T} 4=75 \%$ of the RDF through drip system

$\mathrm{T} 5=100 \%$ of the RDF through drip system

$\mathrm{T} 6=100 \%$ of the RDF through soil application 
Its content was found to decrease with increasing depth of soil and the magnitude of decrease was more prominent in the treatments under drip fertigation. Void ratio is usually considered in parallel with soil porosity, which is defined as the ratio of the volume of voids to the total volume of the soil.

Content of void ratio varied from 0.51 to 0.59 (Table 1) over all the soils under study. The values were not significantly different among the treatments but significant difference was observed across the soil depths. Void ratio resulted in almost similar value (0.57) along soil depths under T6 treatment, but gradually decreased towards soil depths under other drip fertigation treatments. Air filled porosity decreased significantly with increasing soil depths but the effect of different treatments was not found to be significant. The values varied from 0.11 to 0.17 (Table 1) among all the treatments.

Maximum water holding capacity of soils under different treatments across varying soil depths was not significantly different from each other. The treatment-wise average values for water holding capacity under drip fertigation system varied from 42.62 to 44.8 $\%$ (Table 1) in soil.

\section{Status of some chemical properties of soil}

It was observed that soil $\mathrm{pH}$ values ranged between 7.99 and 8.21 in the surface soil in all the treatments were not significantly different. But $\mathrm{pH}$ values with increasing soil depths decreased significantly in all the treatments (Table 2).

This is because coconut has a fibrous root system which consists of an abundance of thin roots that grow outward from the plant near the soil surface and requires high amount of $\mathrm{K}, \mathrm{Mg}$ and $\mathrm{Ca}$ ion (Dhanapal et al.,2000) for their growth and development. Therefore, $\mathrm{Ca}$ and $\mathrm{Mg}$ ion don't get leached downward during drip fertigation across the fibrous root system due to continuous uptake resulting in a decrease in soil $\mathrm{pH}$ at lower depths. The decrease in soil $\mathrm{pH}$ caused by urea applications resulted in large increases in levels of exchangeable Al (Haynes (1988).

Electrical conductivity of soils also significantly decreased with increasing soil depths that may be justified by the uptake of soluble cations like $\mathrm{Ca}, \mathrm{Mg}, \mathrm{K}, \mathrm{Na}$ etc. by the coconut palm which dilute the concentrations of soluble cations at the lower depths of soil., but its content in the soils under different treatments varied from 0.172 to $0.222 \mathrm{dS} \mathrm{m}^{-1}$ (Table 2) which were found to be at par.

Cation exchange capacity (CEC) of soils under drip fertigation treatments was found to be significantly different from each other. Depth-wise CEC values were also significantly different. Its content in soils (Table 2) was found to be increasing with increasing levels of fertilizer treatments in surface soil. Notably, the highest values for CEC were recorded in the $2^{\text {nd }}$ depth of soil $(30-60 \mathrm{~cm})$ under every treatment, which may be due to the effect of continuous downward movement of small sized particles like clay with drip irrigation water.

Most amounts of active roots of coconut palm which are fibrous in nature consists of an abundance of thin roots that grow outward, remains at 30-60 $\mathrm{cm}$ depth of soil (Pillai and Davis, 1963; Ramadasan and Lal, 1966) and leached out materials like clay may deposit there which may collectively increase the CEC content of soil. Among the different drip fertigation treatments, T4 resulted the highest value $\left[16.54 \mathrm{cmol}\left(\mathrm{p}^{+}\right) \mathrm{kg}^{-1}\right]$ which was at par with T5 [16.08 cmol( $\left.\left.\mathrm{p}^{+}\right) \mathrm{kg}^{-1}\right]$. The mean CEC ranged between 10.75 and $13.50 \mathrm{cmol}\left(\mathrm{p}^{+}\right) \mathrm{kg}$ 1 . 
Table.2 Effect of long term (5 years) fertigation on chemical properties of soil under study

\begin{tabular}{|c|c|c|c|c|c|c|c|c|c|c|c|c|c|c|c|c|}
\hline \multirow{2}{*}{$\begin{array}{l}\text { Treat- } \\
\text { ments }\end{array}$} & \multicolumn{4}{|c|}{ pH (1: 2.5) } & \multicolumn{4}{|c|}{$\mathrm{EC}\left(\mathrm{dS} \mathrm{\textrm {m } ^ { - 1 } )}\right.$} & \multicolumn{4}{|c|}{ CEC $\left[\mathrm{cmol}\left(\mathrm{p}^{+}\right) \mathrm{kg}^{-1}\right]$} & \multicolumn{4}{|c|}{ Organic carbon (\%) } \\
\hline & D1 & D2 & D3 & Mean & D1 & D2 & D3 & Mean & D1 & D2 & D3 & Mean & D1 & D2 & D3 & Mean \\
\hline T1 & 8.05 & 7.56 & 7.39 & 7.67 & 0.222 & 0.120 & 0.103 & 0.148 & 9.91 & 10.72 & 11.62 & 10.75 & 0.52 & 0.27 & 0.24 & 0.34 \\
\hline $\mathbf{T} 2$ & 8.03 & 7.74 & 7.56 & 7.78 & 0.216 & 0.134 & 0.133 & 0.162 & 12.83 & 14.45 & 10.60 & 12.42 & 0.55 & 0.28 & 0.26 & 0.36 \\
\hline T3 & 7.99 & 7.65 & 7.43 & 7.69 & 0.215 & 0.139 & 0.138 & 0.158 & 10.18 & 16.54 & 11.43 & 12.90 & 0.55 & 0.25 & 0.20 & 0.33 \\
\hline T4 & 8.05 & 7.60 & 7.45 & 7.70 & 0.186 & 0.149 & & & & & 13.78 & 13.50 & 0.57 & 0.24 & 0.21 & 0.34 \\
\hline T5 & 8.17 & 7.77 & 7.65 & 7.86 & 0.193 & 0.145 & 0.147 & 0.162 & 13.64 & 16.08 & 9.16 & 12.96 & 0.58 & 0.32 & 0.26 & 0.39 \\
\hline T6 & 8.21 & 7.72 & 7.55 & 7.82 & 0.172 & 0.113 & 0.080 & 0.122 & 13.80 & 14.14 & 10.03 & 12.66 & 0.68 & 0.53 & 0.31 & 0.51 \\
\hline Mean & 8.08 & 7.67 & 7.51 & & 0.201 & 0.133 & 0.188 & & 11.96 & 14.53 & 11.10 & & 0.58 & 0.32 & 0.25 & \\
\hline \multicolumn{17}{|c|}{$C D(p=0.05)$} \\
\hline $\mathbf{T}$ & \multicolumn{4}{|c|}{ NS } & \multicolumn{4}{|c|}{ NS } & \multicolumn{4}{|c|}{1.04} & \multicolumn{4}{|c|}{0.09} \\
\hline D & \multicolumn{4}{|c|}{0.11} & \multicolumn{4}{|c|}{0.02} & \multicolumn{4}{|c|}{0.73} & \multicolumn{4}{|c|}{0.06} \\
\hline TxD & \multicolumn{4}{|c|}{ NS } & \multicolumn{4}{|c|}{ NS } & \multicolumn{4}{|c|}{1.79} & \multicolumn{4}{|c|}{ NS } \\
\hline CV(\%) & \multicolumn{4}{|c|}{2.45} & \multicolumn{4}{|c|}{2.29} & \multicolumn{4}{|c|}{10.09} & \multicolumn{4}{|c|}{2.79} \\
\hline
\end{tabular}

D1: 0 - $30 \mathrm{~cm}$ soil depth, D2: 30-60 $\mathrm{cm}$ soil depth, D3: 60-90 $\mathrm{cm}$ soil depth

$\mathrm{T} 1=$ Control (No fertilizer)

$\mathrm{T} 2=25 \%$ of the recommended dose of NPK fertilizers (RDF) through drip system

$\mathrm{T} 3=50 \%$ of the RDF through drip system

$\mathrm{T} 4=75 \%$ of the RDF through drip system

$\mathrm{T} 5=100 \%$ of the RDF through drip system

$\mathrm{T} 6=100 \%$ of the RDF through soil application 
Organic carbon content varied significantly among all the treatments and also across the varying soil depths. Its overall content was found to be medium that ranged between $0.52 \%$ in control (T1) and $0.68 \%$ (Table 2 ) in treatment T6 (soil application of chemical fertilizer) in surface soil $(0-30 \mathrm{~cm})$.

Treatments which included the application of higher amount of chemical fertilizers resulted in comparatively higher content of organic carbon in soil because it may increase the growth of weeds which may add to the soil organic carbon after dying in-situ (Acharya et al.,2015) and reflected in the treatment effects.

The relatively large soil organic carbon in the top layer under all aspect directions is attributable to higher OM inputs from the aboveground biomass and more microbial abundance compared to the lower depths (Dorji et al., 2014) and depth wise its content decreased in all the treatments.

Available nitrogen content was low in all the treatments which ranged between 47.21 $\mathrm{mg} / \mathrm{kg}$ for $\mathrm{T} 1$ and $75.12 \mathrm{mg} \mathrm{kg}-1$ for $\mathrm{T} 5$ treatment (Table 3). Its content was increasing with increasing amount of chemical fertilizers in the treatments under drip irrigation.

All the treatments resulted in significantly different values for available nitrogen content. Highest content of available nitrogen was found in T5 treatment (75.12 mg kg-1) which was at par with the T4 treatment $(69.81 \mathrm{mg}$ $\mathrm{kg}-1)$ and significantly different from all other treatments.

There was no significant difference between the total nitrogen content in soils under different treatments. But its content in treatments receiving chemical fertilizers was much higher than that of the control treatment (258.93 mg kg-1).
This is due to application of urea and DAP in soil through drip irrigation reduces the chances of volatilization loss of nitrogen which may increase its content in soil with increasing levels of fertilizer. In different treatments Available form of nitrogen was found in between 15.44-18.23\% of the total nitrogen content in the soil.

Available phosphorous content was medium in all the treatments except control $(8.40 \mathrm{mg}$ $\mathrm{kg}$-1) which ranged between 10.34 in $\mathrm{T} 2$ to $18.84 \mathrm{mg} \mathrm{kg}-1$ for T5 treatment (Table 3).

Highest content of available phosphorous was found in T5 treatment (18.84 mg kg-1) which was at par with the T4 (16.07 mg kg-1), T6 (16.59 mg kg-1) treatment as well as marginally at par with $\mathrm{T} 3(11.85 \mathrm{mg} \mathrm{kg}-1)$ and significantly different from all other treatments that may be due to fixation of $\mathrm{P}$ under soil application immediately after application.

There was no significant difference between the total phosphorous content in soils under different treatments. But its content in treatments receiving chemical fertilizers was much higher than that of the control treatment (285.02 mg kg-1).

An increasing content of total phosphorus in soil was found with increasing levels of chemical fertilizers in drip fertigation treatments.

Available form of phosphorous was found to be between 2.9 and $5.2 \%$ of the total phosphorous content in the soil across the different treatments.

Available potassium content was low to medium in all the treatments which ranged between $49.53 \mathrm{mg} \mathrm{kg}-1$ for $\mathrm{T} 1$ and $78.44 \mathrm{mg}$ $\mathrm{kg}-1$ for $\mathrm{T} 5$ treatment (Table 3 ). 
Table.3 Effect of long term (5 years) fertigation on $\mathrm{N}, \mathrm{P}, \mathrm{K}$ and $\mathrm{S}$ content $\left(\mathrm{mg} \mathrm{kg}^{-1}\right.$ ) in soils under study (Avg. value of $0-90 \mathrm{~cm}$ depth)

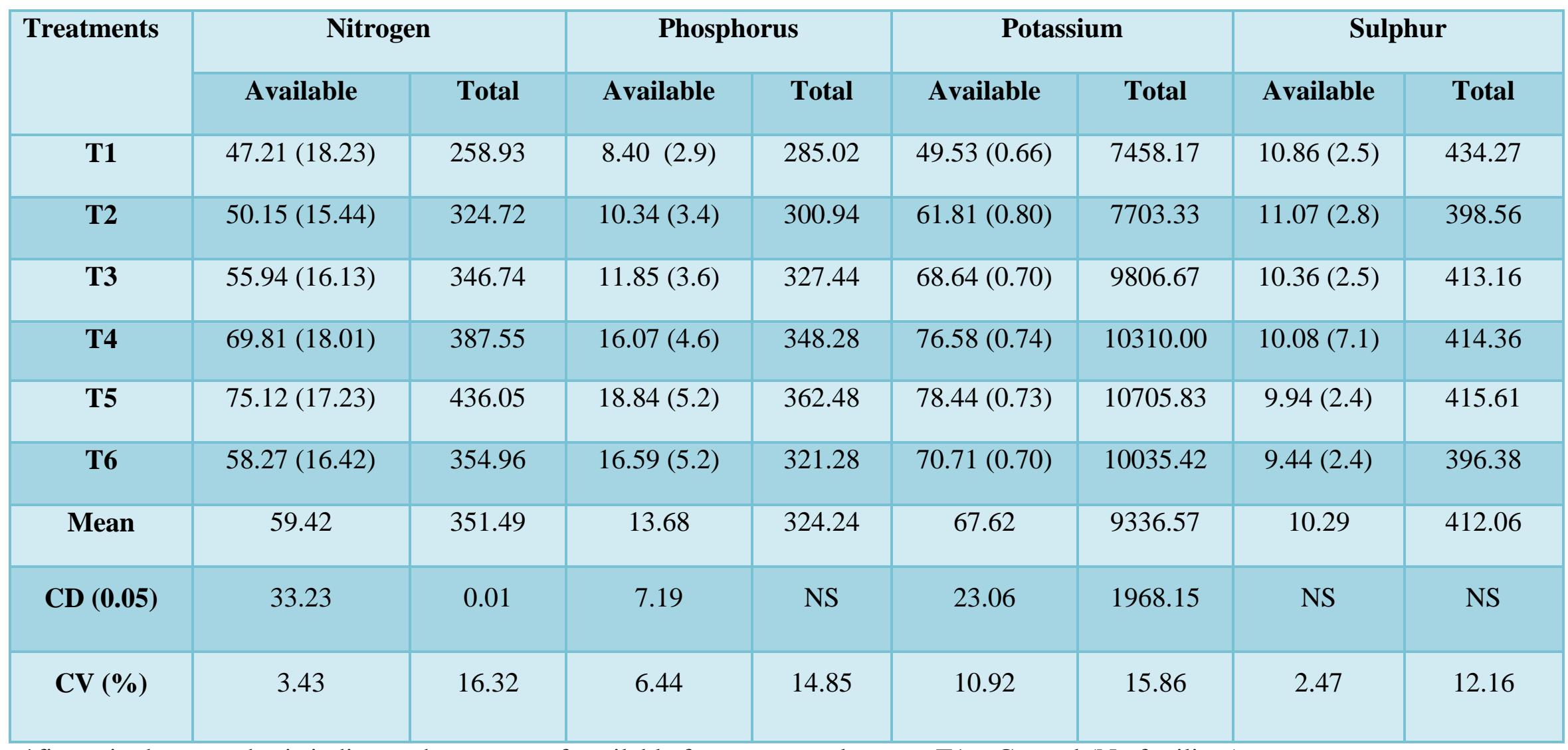

*figure in the parenthesis indicates the percent of available form over total contentT1 $=$ Control (No fertilizer)

$\mathrm{T} 2=25 \%$ of the recommended dose of NPK fertilizers (RDF) through drip system

$\mathrm{T} 3=50 \%$ of the RDF through drip system

$\mathrm{T} 4=75 \%$ of the RDF through drip system

$\mathrm{T} 5=100 \%$ of the RDF through drip system

T6 $=100 \%$ of the RDF through soil application 
Highest content of available potassium was found in T5 treatment (78.44 mg kg-1) which was at par with the T3 (68.64 mg kg-1), T4 (76.58 mg kg-1) and T6 (70.71 mg kg-1) treatments and significantly different from all other treatments that may be due to uptake of potassium by the palm as immediate effect and / or leaching of highly soluble potassium during monsoon season.

There was no significant difference between the total potassium content in soils under different treatments. But its content in treatments receiving chemical fertilizers was much higher than that of the control treatment (7458.17 mg kg-1).

An increasing content of total potassium in soil was found with increasing levels of chemical fertilizers in drip fertigation treatments. Available form of potassium was found to be between $0.66-0.80 \%$ of the total potassium content in the soil across the different treatments.

Available sulphur content ranged between $9.44 \mathrm{mg} \mathrm{kg}-1$ for T6 and $11.07 \mathrm{mg} \mathrm{kg}-1$ for T2 treatment (Table 3). All the treatments values were not significantly different for available sulphur content.

Treatments receiving higher doses of chemical fertilizer resulted in comparatively lower values of available sulphur content in soil. There was no significant difference between the total sulphur content in soils under different treatments.

But its content in treatments receiving chemical fertilizers was comparatively lower than that of the control treatment $(434.27 \mathrm{mg}$ $\mathrm{kg}$-1) fertilizers that may be explained by the uptake of higher amount of sulphur from soil along with NPK through chemical fertilizer to maintain nutrient balance in the palm.
Available form of sulphur was found to be between $2.4-7.1 \%$ of the total phosphorous content in the soil across the different treatments. Available Fe content was found to be in the range between $15.67 \mathrm{mg} \mathrm{kg}^{-1}$ for T6 and $17.34 \mathrm{mg} \mathrm{kg}^{-1}$ (Table 4) for T5 treatment.

All the treatments were not significantly different for available Fe content. Treatments receiving higher doses of chemical fertilizer resulted in comparatively lower values of available iron content in soil.

Available form of $\mathrm{Fe}$ was found to be between $0.5-0.7 \%$ of the total Fe content in the soil across the different treatments. Available Mn content ranged between 11.95 $\mathrm{mg} \mathrm{kg}{ }^{-1}$ for $\mathrm{T} 2$ and $13.02 \mathrm{mg} \mathrm{kg}^{-1}$ for $\mathrm{T} 1$ treatment (Table 4). All the treatments were not significantly different. Highest content of available $\mathrm{Mn}$ was found in $\mathrm{T} 1$ treatment (13.02 $\mathrm{mg} \mathrm{kg}^{-1}$ ).

Comparatively lower values of available manganese content in soil were found in the treatments receiving higher doses of chemical fertilizers. 2.4 to $3.3 \%$ of the total Mn content was found as available form of $\mathrm{Mn}$ in soil across the different treatments.

Available Zn content was recorded (Table 4) to be in the range of $0.37 \mathrm{mg} \mathrm{kg}^{-1}$ for $\mathrm{T} 1$ and $0.41 \mathrm{mg} \mathrm{kg}^{-1}$ for $\mathrm{T} 5$ treatment. All the treatments were not significantly different from each other. Highest content of available $\mathrm{Zn}$ was found in T5 treatment $\left(0.41 \mathrm{mg} \mathrm{kg}^{-1}\right)$.

Available form of $\mathrm{Zn}$ was found to be between $0.8-0.9 \%$ of the total $\mathrm{Zn}$ content in the soil across the different treatments. Available $\mathrm{Cu}$ content in the different treatments varied (Table 4) from 0.84 to 0.87 $\mathrm{mg} \mathrm{kg}^{-1}$ soil and all the treatments were not significantly different. Highest content of available $\mathrm{Cu}$ was found in control (T1) and T6 treatment $\left(0.87 \mathrm{mg} \mathrm{kg}^{-1}\right)$. 
Table: 4 Effect of long term (5 years) fertigation on micronutrient (Fe, Mn, Zn, Cu and B) content (mg kg ${ }^{-1}$ ) in soils (Avg. value of 0-90 cm depth)

\begin{tabular}{|c|c|c|c|c|c|c|c|c|c|c|}
\hline \multirow[t]{2}{*}{ Treatments } & \multicolumn{2}{|c|}{$\mathbf{F e}$} & \multicolumn{2}{|c|}{ Mn } & \multicolumn{2}{|c|}{$\mathbf{Z n}$} & \multicolumn{2}{|c|}{$\mathbf{C u}$} & \multicolumn{2}{|c|}{ B } \\
\hline & Available & Total & Available & Total & Available & Total & Available & Total & Available & Total \\
\hline T1 & $18.88(0.7)^{*}$ & 2581.91 & $13.02(2.8)$ & 464.73 & $0.37(0.8)$ & 46.88 & $0.87(5.4)$ & 16.23 & $0.29(0.17)$ & 167.39 \\
\hline $\mathbf{T 2}$ & $18.27(0.7)$ & 2602.76 & $11.95(2.4)$ & 501.60 & $0.39(0.8)$ & 46.04 & $0.84(4.5)$ & 18.67 & $0.28(0.18)$ & 153.52 \\
\hline T3 & $18.16(0.6)$ & 2629.87 & $12.43(2.8)$ & 437.89 & $0.39(0.9)$ & 44.33 & $0.84(5.0)$ & 16.92 & $0.28(0.21)$ & 135.96 \\
\hline T4 & $17.68(0.6)$ & 2693.14 & $12.64(3.0)$ & 417.92 & $0.40(0.9)$ & 45.85 & $0.86(6.1)$ & 14.08 & $0.28(0.15)$ & 183.10 \\
\hline T5 & $17.34(0.6)$ & 2646.25 & $12.69(3.2)$ & 402.28 & $0.41(0.9)$ & 44.10 & $0.85(5.7)$ & 15.01 & $0.28(0.18)$ & 159.29 \\
\hline T6 & $15.67(0.5)$ & 2643.75 & $12.64(3.3)$ & 379.59 & $0.38(0.9)$ & 43.92 & $0.87(6.3)$ & 13.89 & $0.26(0.17)$ & 151.46 \\
\hline Mean & 17.67 & 2629.61 & 12.56 & 434.00 & 0.39 & 45.19 & 0.86 & 15.80 & 0.28 & 158.45 \\
\hline $\begin{array}{c}\text { CD } \\
(p=0.05)\end{array}$ & NS & NS & NS & NS & NS & NS & NS & NS & NS & 18.64 \\
\hline $\mathrm{CV}(\%)$ & 3.15 & 3.61 & 14.90 & 3.08 & 3.41 & 12.03 & 7.53 & 2.64 & 5.75 & 14.44 \\
\hline
\end{tabular}

*figure in the parenthesis indicates the percent of available form over total content $\mathrm{T} 1=$ Control (No fertilizer)

$\mathrm{T} 2=25 \%$ of the recommended dose of NPK fertilizers (RDF) through drip system $\mathrm{T} 3=50 \%$ of the RDF through drip system

$\mathrm{T} 4=75 \%$ of the RDF through drip system

$\mathrm{T} 5=100 \%$ of the RDF through drip system

T6 $=100 \%$ of the RDF through soil application 
Percent contribution of available form of $\mathrm{Cu}$ to the total content of $\mathrm{Cu}$ was found in between $4.5-6.3 \%$ across the different treatments. Micronutrient content in the soil decreased with increasing levels of applied chemical fertilizers that may be explained by the uptake of higher amount of micronutrient from soil along with NPK through chemical fertilizer to maintain nutrient balance in the palm.

Therefore, iron, manganese, zinc, copper and boron content were lower in the treatment applied with higher doses of chemical NPK fertilizers

Available B content was found to be low in the range (Table 4) between 0.26 and $0.29 \mathrm{mg}$ $\mathrm{kg}^{-1}$. All the treatment values were not significantly different for available B content in soil. Available form of B was found to be between $0.17-0.21 \%$ of the total B content in the soil across the different treatments.

All the treatments under drip fertigation study for dehydrogenase activity of soil was significantly different from each other and across the soil depths also and resulted data is presented in table 5 .

Its value was increasing significantly with increasing levels of fertilizer in the treatments and was decreasing significantly across the soil depths.

Highest values of dehydrogenase activity of soil found in both T5 $(29.62,22.17,11.14 \mu \mathrm{g}$ TPF $\mathrm{h}^{-1} \mathrm{~g}^{-1}$ dry soil) and T6 (29.23, 21.29, $11.54 \mu \mathrm{g}$ TPF $\mathrm{h}^{-1} \mathrm{~g}^{-1}$ dry soil) treatments across the soil depths that probable due to being differences in organic carbon content in the treatment and across the soil depths also.

Table 5 Effect of long term (5 years) fertigation on dehydrogenase activity $\left(\mu \mathrm{g}\right.$ TPF h${ }^{-1} \mathrm{~g}^{-1}$ dry soil) in soil

\begin{tabular}{|c|c|c|c|c|}
\hline Treatments & D1 & D2 & D3 & Mean \\
\hline T1 & 7.39 & 5.19 & 3.12 & 5.23 \\
\hline T2 & 8.07 & 7.92 & 6.2 & 7.40 \\
\hline T3 & 13.83 & 11.3 & 7.39 & 10.84 \\
\hline T4 & 25.26 & 16.84 & 7.48 & 16.53 \\
\hline T5 & 29.62 & 22.17 & 11.14 & 20.98 \\
\hline T6 & 29.23 & 21.29 & 7.81 & \\
\hline Mean & 18.90 & 14.12 & & \\
\hline CD (p=0.05) & & 1.55 & & \\
\hline T & & 1.08 & \\
\hline D & & 2.69 & \\
\hline CV $(\%)$ & & 13.92 & \\
\hline
\end{tabular}


This study was taken in All India Coordinated Research Project on Coconut under drip fertigation system. Coconut needs irrigation on a regular basis which helps in improving the nut bearing capacity and quality of the nuts. Drip fertigation allows continuous irrigation and fertilizer injection into the root zone.

Soil physiochemical properties are important aspects of soil quality that can change with long-term drip irrigation. In order to generate information under long term (5 years) drip fertigation, the present investigation was undertaken to evaluate the soil fertility status under drip fertigation system in coconut at different nutrient levels through drip fertigation.

The results of the present investigation indicate that bulk density, particle density and pore space of soils were found to have no significant difference among the treatments and across different soil depths. Bulk density, particle density and pore space varied from 1.41 to $1.47 \mathrm{Mg} \mathrm{m}^{-3}, 2.23$ to $2.25 \mathrm{Mg} \mathrm{m}^{-3}$, and 31.9 to $36.6 \%$, respectively, among all soils. Void ratio varied from 0.51 to 0.59 over all the soils.

Void ratio and air-filled porosity were not significantly different among the treatments but significant difference was observed across the soil depths. Maximum water holding capacity of soils under different treatments across varying soil depths was not significantly different from each other.

Soil $\mathrm{pH}$ and EC of all the treatments was not significantly different but decreased significantly with increasing soil depths. All the treatments for CEC and organic carbon content of soils were not found to be significantly different and depth-wise were significantly different. Organic carbon content varied significantly among all the treatments and also across the varying soil depths.
Available nitrogen, phosphorus and potassium content were low, medium and low to medium respectively. All the treatments were significantly different for available nitrogen, phosphorus and potassium content in soil.

Highest content of these three nutrients was found in T5 treatment. Sulphur content in soil was at border of medium and all the treatments were at par. All the treatments values were not significantly different for available sulphur content in soil. Total nitrogen and potassium content in all the treatments were significant different but total phosphorus and sulphur content were not significantly different.

Iron, manganese, zinc, copper and boron content in all the treatment were not significantly different from each other. Dehydrogenase activity of studied soil was increasing significantly with increasing levels of fertilizer in the treatments and was decreasing significantly across the soil depths.

All the treatments for available $\mathrm{N}, \mathrm{P}$ and $\mathrm{K}$ were significantly different across the soil depths. T5 treatment resulted in highest value for available N, P and $\mathrm{K}$ at each depth of soil and T4 treatment also resulted near to highest value in each depth of soil. But sulphur content was non-significantly decreasing with increasing levels fertilizers in the treatments and decreased across the soil depths also.

Available iron, manganese and zinc content in soil across the soil depths under different treatments were significantly different. Available copper and boron content across the soil depths were significantly different. Lower values of available $\mathrm{Cu}$ and $\mathrm{B}$ were obtained in the treatments receiving higher doses of fertilizer across all soil depths. Total content of these micronutrients in soils under different treatments and across the soil depths were significantly different from each other. Thus, 
T5 treatment was found as a best treatment for the coconut.

It is concluded that the results of the present investigation indicate that bulk density, particle density and pore space of soils were found to have no significant difference among the treatments. Bulk density, particle density and pore space varied from 1.41 to $1.47 \mathrm{Mg}$ $\mathrm{m}^{-3}, 2.23$ to $2.25 \mathrm{Mg} \mathrm{m}^{-3}$, and 31.9 to $36.6 \%$, respectively, among all soils.

Void ratio varied from 0.51 to 0.59 over all the soils. Void ratio and air-filled porosity were not significantly different among the treatments. Soil $\mathrm{pH}$ and EC of all the treatments was not significantly different. All the treatments for CEC and organic carbon content of soils were not found to be significantly different.

Organic carbon content varied significantly among all the treatments and also across the varying soil depths. Available nitrogen, phosphorus and potassium content were low, medium and low to medium respectively. All the treatments were significantly different for available nitrogen, phosphorus and potassium content in soil.

Highest content of these three nutrients was found in T5 treatment. Sulphur content in soil was border of medium and all the treatments were at par. All the treatments values were not significantly different for available sulphur content in soil.

Total nitrogen and potassium content in all the treatments were significant different but total phosphorus and sulphur content were not significantly different. Iron, manganese, zinc, copper and boron content in all the treatment were not significantly different from each other. Dehydrogenase activity of studied soil was increasing significantly with increasing levels of fertilizer in the treatments and was decreasing significantly across the soil depths.

Majority of the physicochemical properties of soil under the different fertigation levels do not differ significantly. Only CEC and organic carbon content in soil significantly increases with increasing levels of fertilizer in the treatments.

Available N, P and $\mathrm{K}$ content in soil increases significantly with increasing levels of NPK fertilizers in the treatments but $S$ and micronutrients like $\mathrm{Fe}, \mathrm{Mn}, \mathrm{Cu}, \mathrm{Zn}$ and $\mathrm{B}$ contents remain similar.

Dehydrogenase activity of soil increases significantly with increasing fertigation levels. These data after this research can be helpful for the further research \& more research also required for other parameters also which was not covered in this research.

\section{References}

Acharya GC, Paul SC, Chakrabarty R and Ray AK (2015). Effect of organic and inorganic sources of nutrients on soil fertility status of arecanut (Areca catechu) in north-east India. Indian Journal of Agricultural Sciences, 85(10): 1335-41.

Adeniyan O, Ojeniyi S (2006). Effect of poultry manure, NPK 15-15-15 and combination of their reduced levels on maize growth and soil chemical properties. Nigerian J. Soil Sci., 15(1):34-41.

Amer KH, Midan SA, Hatfield JL (2009) Effect of deficit irrigation and fertilization on cucumber. Agronomy Journal 101(6), 1556-1564.

Bar-Yosef B, (1999). Advances in fertigation. Advances in Agronomy, 65:1-70.

Berger KC, Truog E (1939). Boron determination in soils and plants. Industrial \& Engineering 
Chemistry Analytical Edition, 11(10): 540-545.

Black CA (1965). Methods of Soil Analysis, Parts 1 \& 2, American Society of Agronomy.1nc., Publisher, Madicen, Wisconsin, USA, 1-1378.

Bucks DA, \& S Davis (1986). Trickle Irrigation for Crop Production.Chapter 1: Historical development. FS Nakayama, DA Bucks eds. Amsterdam, The Netherlands: Elsevier.

Clark L. (2004). Changes in properties of vineyard red brown earths under longtermd drip irrigation combined with varying water qualities and gypsum application rates. $\mathrm{PhD}$ thesis. The university of Adelaide. Adelaide.

Cockroft B and Olsen KA (2000). Degradation of soil structure due to coalescence of aggregates in no-till, no traffic bed in irrigated crops. Australian Journal of Soil Research, 38: 67-70.

Dhanapal R, Maheswarappa HP, Subramanian P (2000). Response of coconut roots to the methods of irrigation in littoral sandy soil. Journal of Plantation Crops 28(3): 208-11.

Efthimiadou A, Bilslis D, Karkanis A, Froud Williams B (2010). Combined organic/ inorganic fertilization enhances soil quality and increased yield, photosynthesis and sustainability of sweet maize crop. Australian Journal of Crop Science 4(9), 722-729.

Haynes RJ (1988). Comparison of fertigation with broadcast applications of urea-N on levels of available soil nutrients and on growth and yield of trickle-irrigated peppers. Scientia Horticulturae, 35:189198.

INCID (2006). Drip Irrigation-Prospects and Coverage in India. Indian National Committee on Irrigation and Drainage, Ministry of water resources, New Delhi.

Jackson ML (1973). Soil Chemical Analysis. Prentice Hall India Pvt. Ltd., New
Delhi, 498.

Jat R, Wani S, Sahrawat K, Piara Singh, D, (2011). Fertigation in vegetable crops for higher productivity and resource use efficiency. I Ind. J. Fer. 7: 22-37.

John MK, Chuah HH, and Neufield JH (1975). Application of improved azomethine-H method to the determination of boron in soils and plants: Analytical Left, 8: 559-568.

Keen BA and Raczkowski H (1921). Relation between the clay content and certain physical properties of a soil. Journal of Agricultural Science, 11: 441-449.

Klein DA, Loh TC, Goulding RL (1971). A rapid procedure to evaluate dehydrogenase activity in soil of low organic matter. Soil Biology and Biochemistry, 3: 385-387.

Lindsay WL, Norvell WA (1978). Development of DTPA soil test for zinc, iron, manganese and copper. Soil Science Society of American Journal, 42:421-428.

Olsen SR, Cole CV, Watanabe FS, Dean LA (1954). Estimation of available phosphorus in soils by extraction with sodium bicarbonate. Gov. Printing Office Washington DC. USDA Circular. 939: 1-19.

Page AL, Miller RH and Keeney DR (eds) (1982). Methods of Soil Analysis: Part 2, Chemical and Microbiological Properties. Agronomy Series No 9, American Society of Agronomy, Madison, WI.

Patel N, Rajput TBS (2011). Simulation and modeling of water movement in potato (Solanum tuberosum).The Ind. J Agrl. Sci. 81, 25-32.

Pillai NG, Davis TA (1963). Exhaust of macronutrients by coconut palmpreliminary study. Indian Coconut Journal, 16:81-7.

Piper CS, (1966). Soil and Plant Analysis. Hans publishers, Bombay. 
Ramadasan A, Lal SB (1966). Exhaust of nutrients from coconut garden - Factors affecting production. Coconut Bulletin, 20:173-5.

Schollenberger CJ (1927). Exchangeable hydrogen and soil reaction. Science, 35:552-553.

Subbiah BV, Asija GL (1956). A rapid procedure for the estimation of available nitrogen in soils. Current Science, 25:259-266.

Walkley A and Black CA (1934). An examination of wet acid method for determining soil organic matter and a proposed modification of the chromic acid titration method. Soil Science, 37:29-38.

Williams CH and Steinbergs A (1959). Soil sulphur fractions as chemical indices of available sulphur in some Australian soils. Australian Journal of Agricultural Research, 10:340-352.

WRI (2007). Annual Report of World Resources Institute-2006-07. www. wri. Org /publication /wri-annual-report2006.

\section{How to cite this article:}

Avinash Sarin Saxena, Sankar Chandra Paul, Amit Kumar Pradhan, Rajiv Rakshit, Ruby Rani, Deepak Ranjan Kishor, Chandan Kumar Bagchi. 2020. Soil Fertility Status in Coconut after Long-term Drip Fertigation in Indo-gangetic Plain of South Bihar Alluvial Zone(a). Int.J.Curr.Microbiol.App.Sci. 9(02): 365-380. https://doi.org/10.20546/ijcmas.2020.902.046 